\title{
A 10-year-old girl presenting with jaundice, deterioration of school performance and itching
}

\author{
Md. Benzamin, Zannatul Ferdous Sonia, Md. Rukunuzzaman, Khan Lamia Nahid and \\ Bishnu Pada Dey
}

\section{Article Info \\ Department of Pediatric Gastroenterolo- gy and Nutrition, Faculty of Pediatrics, Bangabandhu Sheikh Mujib Medical University, Shahbag, Dhaka, Bangladesh (MB, ZFS, MR, KLN); Department of Pathology, Faculty of Basic Science and Paraclinical Science, Bangabandhu Sheikh Mujib Medical University, Shahbag, Dhaka Bangladesh (BPD) \\ For Correspondence: \\ Md. Benzamin \\ drmd.benzamin@yahoo.com \\ Received: \\ Accepted: \\ 28 September 2019 \\ Available Online: 24 December 2019}

ISSN: 2224-7750 (Online)

2074-2908 (Print)

DOI: 10.3329/bsmmuj.v12i4.43325

Keywords: Itching; Jaundice; School performance; Wilson's disease

Cite this article:

Benzamin $\mathrm{M}$, Sonia ZF, Rukunuzzaman M, Nahid KL, Dey PD. A 10-year-old gir presenting with jaundice, deterioration of school performance and itching. Bangabandhu Sheikh Mujib Med Univ J. 2019; 12: 192-198.

\section{Copyright:}

The copyright of this article is retained by the author(s) [Atribution CC-By 4.0]

Available at:

www.banglajol.info

A Journal of Bangabandhu Sheikh Mujib Medical University, Dhaka, Bangladesh
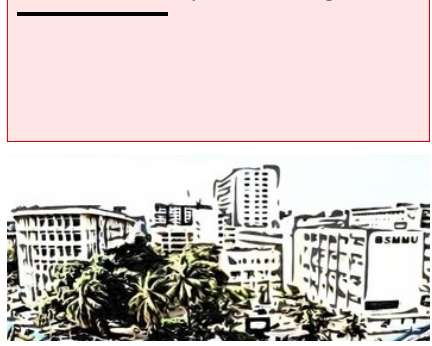

\section{Presentation of Case}

Dr. Zannatul Ferdous Sonia (Resident): A 10-yearold immunized girl, $6^{\text {th }}$ issue of consanguineous parents, presented with the complaints of jaundice for the last 2 years and deterioration of school performance for the same duration. She also had generalized itching for the last 6 months. She had no history of altered sleep pattern, any gastrointestinal bleeding, surgical or dental procedures, history of blood and blood products transfusion, taking any offending drugs, sib death or family history of such type of illness. For these above mentioned complaints, she was treated with traditional healers. On examination, she was alert, moderately pale, deeply icteric, BCG mark present, hepatomegaly $(4 \mathrm{~cm}$ from right costal margin, sharp border, firm in consistency, nontender). The spleen was just palpable and ascites was present as evidenced by shifting dullness. Other systemic examination revealed normal findings. Investigations revealed mild anemia (hemoglobin $10.3 \mathrm{~g} / \mathrm{dL}$; Table I). Peripheral blood film shows microcytic hypochromic anemia with no features of hemolysis. Serum total bilirubin level was $21.3 \mathrm{mg} / \mathrm{dL}$. Direct bilirubin level was 13.1 $\mathrm{mg} / \mathrm{dL}$. The alanine aminotransferase level was raised (324 U/L), prothrombin time prolonged (28 sec, INR-2.35), serum albumin level was low $(26 \mathrm{~g} / \mathrm{L})$. HBsAg and anti$\mathrm{HCV}$ were negative. The ultrasonography of whole abdomen showed features suggestive of chronic liver disease. Based on the history, physical examinations and laboratory investigations, the diagnosis was chronic liver disease due to Wilson's disease.

\section{Provisional Diagnosis \\ Chronic liver disease due to Wilson's disease}

\section{Differential Diagnosis}

Dr. Md. Benzamin (Resident): As viral marker and Wilson's disease screening were negative and the patient is female, we differentially thought about chronic liver disease due to autoimmune hepatitis.

\section{Wilson's disease}

Dr. Sonia: Wilson's disease is an autosomal recessive disorder affecting copper metabolism due to mutation of ATP7B gene on chromosome 13.1 It causes impaired excretion of copper through bile and decrease incorporation into ceruloplasmin causing excessive copper accumulation in different organs like liver, brain and cornea. Wilson's disease takes at least 3 years to manifest though copper start accumulating soon after birth.? Clinical presentation of Wilson's disease is highly variable. Liver disease and neuropsychiatric features are common presentation. Patients with liver disease tend to be younger than those with neuropsychiatric manifestation. $\frac{3}{3}$ Hepatic presentation can vary from biochemical abnormalities to any spectrum of liver disease including acute hepatitis, acute liver failure and cirrhosis with portal hypertension. $4,5,6$ Some patients may have unusual presentation like hepatic hydrothorax.? Diagnosis of Wilson's disease is based on the combination of clinical findings, few supporting investigations, like presence of KF ring by slit lamp examination, serum ceruloplasmin level $(<20 \mathrm{mg} / \mathrm{dL}), 24$ hours urinary copper $>100 \mathrm{mcg} / 24$ hours and hepatic copper (>250 mcg/g dry weight) estimation. $\underline{8}$ Prompt treatment is required to prevent progression of disease.

\section{Autoimmune hepatitis}

Dr. Benzamin: Autoimmune hepatitis is a progressive inflammatory hepatopathy. If untreated lead to end stage liver disease, requiring liver transplantation. Autoimmune hepatitis is characterized biochemically by increased transaminase levels and serologically by circulating autoantibodies and high immunoglobulin G (IgG) levels, histologically by interface hepatitis, in absence of known etiology. Autoimmune hepatitis can present at any age and in all ethnic groups, but it is more common in women.9-13 Family history of autoimmune disease is frequent $(40 \%)$ in autoimmune 


\begin{tabular}{|c|c|c|}
\hline \multicolumn{3}{|c|}{ Table I } \\
\hline \multicolumn{3}{|c|}{ Laboratory investigations } \\
\hline Investigations & Results & Reference \\
\hline Hemoglobin (g/dL) & 10.3 & $11.5-16.0$ \\
\hline White blood cells $\left(/ \mathrm{mm}^{3}\right)$ & 4,000 & $4,500-11,000$ \\
\hline Platelet $\left(/ \mathrm{mm}^{3}\right)$ & $1,50,000$ & $1,50,000-450,000$ \\
\hline \multicolumn{3}{|l|}{ Serum bilirubin } \\
\hline Total (mg/dL) & 21.3 & $0.2-1.2$ \\
\hline Direct $(\mathrm{mg} / \mathrm{dL})$ & 13.1 & $<0.25$ \\
\hline Prothrombin time (sec) & 28 & $12-16$ \\
\hline International normalized ratio & 2.35 & $<1.4$ \\
\hline $\begin{array}{l}\text { Serum alanine aminotransferase } \\
(\mathrm{U} / \mathrm{L})\end{array}$ & 324 & $35-50$ \\
\hline Serum albumin $(\mathrm{g} / \mathrm{L})$ & 26 & $35-50$ \\
\hline HBs Ag & Negative & \\
\hline Anti-HCV & Negative & \\
\hline Serum ceruloplasmin & $25 \mathrm{mg} / \mathrm{dL}$ & \\
\hline 24 hours urinary copper & $56 \mu \mathrm{g} /$ day & \\
\hline Total IgG & $29.8 \mathrm{~g} / \mathrm{L} \uparrow$ & \\
\hline Anti-nuclear antibody & Negative & \\
\hline $\begin{array}{l}\text { Anti-liver kidney microsomal anti- } \\
\text { body }\end{array}$ & Negative & \\
\hline Anti-mitochondrial antibody & Negative & \\
\hline Coomb's test (direct and indirect) & Negative & \\
\hline Anti HAV IgM & Negative & \\
\hline Anti HEV IgM & Negative & \\
\hline Serum free thyroxine $(\mathrm{ng} / \mathrm{dL})$ & 4.4 & $4.5-12.5$ \\
\hline $\begin{array}{l}\text { Thyroid stimulating hormone } \\
(\mu \mathrm{IU} / \mathrm{mL})\end{array}$ & 40 & $0.7-5.7$ \\
\hline Thyroglobulin antibody & Positive & \\
\hline
\end{tabular}

hepatitis.9 The diagnosis is based on combination of clinical, biochemical, immunological, histological features and exclusion of liver diseases (like hepatitis B, C, E, Wilson's disease, non-alcoholic steatohepatitis and drug induced liver disease) that may share serological and histological features with autoimmune hepatitis. Liver biopsy is required to confirm the diagnosis and to evaluate the severity of liver disease. $.9,13,14$

Dr. Mukesh Khadga (Resident): After evaluating the patient's presenting features, physical findings and the laboratory test results, she was considered for further investigation. For the diagnosis of Wilson's disease, serum ceruloplasmin level was done which was normal $(25 \mathrm{mg} / \mathrm{dL})$. The urinary copper level was also normal (56 mcg/24 hour). The slit lamp examination of eye showed no K-F ring and sunflower cataract. Therefore, the Wilson's disease was excluded.

Dr. Benzamin: To reach the other diagnosis (autoimmune hepatitis), we did following the investigations- IgG-raised (29.8 g/L), antinuclear antibody -negative, Anti LKM1-negative, anti mitochondrial antibody-negative, Coomb's test (direct and indirect)-negative, anti-HAV IgM and anti-HEV IgM-negative. As she had itching and direct bilirubin increased, we did MRCP to exclude obstructive cause and it revealed features suggestive of chronic liver disease with portal hypertension with multiple regenerative nodules and moderate ascites. But as all these were negative, we went for liver biopsy.

Dr. Bishnu Pada Dey (Assistant Professor): Histopathology of liver tissue showed expanded portal areas containing many chronic inflammatory cells (Figure 1A). Marked piecemeal necrosis (interface hepatitis) and moderate lobular inflammation present. Small number of hepatocytes show rossete formation. Bridging fibrosis is present. Features consistent with autoimmune hepatitis.

Dr. Khadga: So, we finally got clue that it was a case of autoimmune hepatitis. Then some investigations

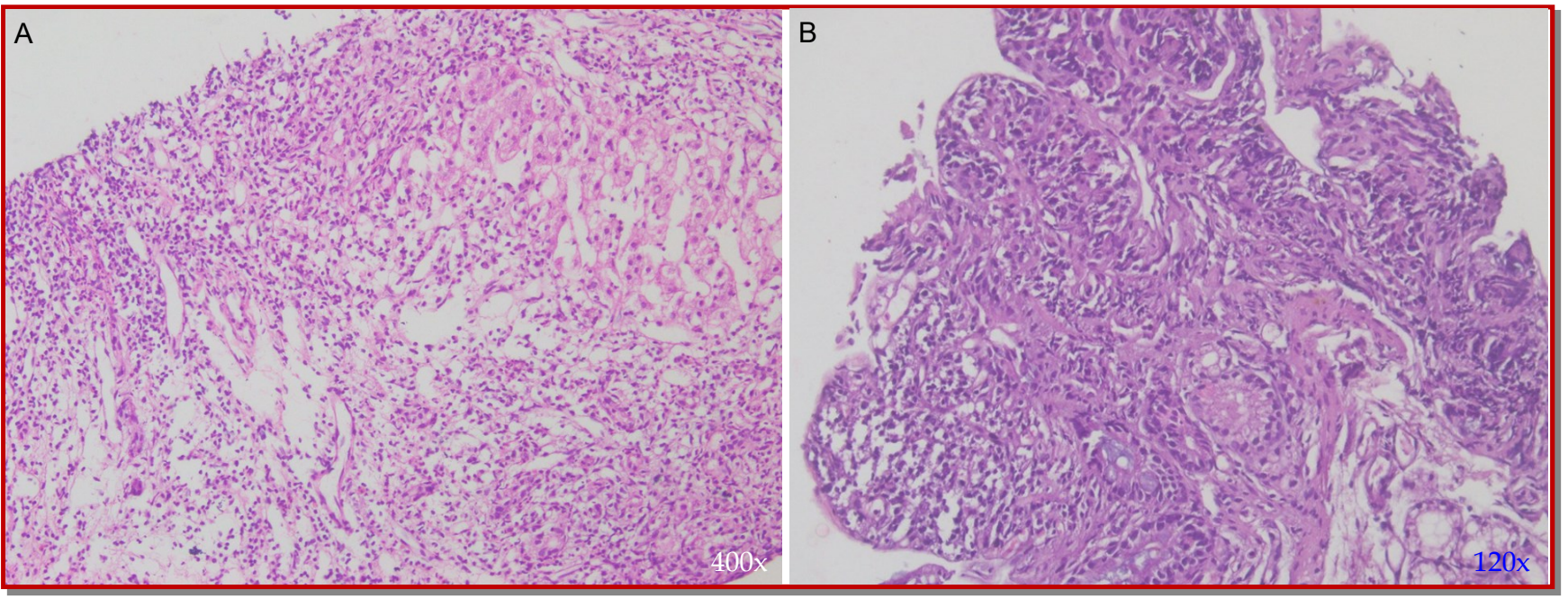

Figure 1: Section of liver tissue showing plasma cell rich portal inflammation, interface hepatitis, hepatocyte rosette formation and emperipolesis (A); Section of duodenal mucosa showing marked villous atrophy with crypt hyperplasia, moderate infiltration of lymphocytes in the lining epithelium and marked infiltration of chronic inflammatory cells including many plasma cells in the lamina propria (B); Hematoxilin and Eosin staining 
were done. Tissue transglutaminase IgA was negative. Serum TSH level was high $(40 \mu \mathrm{IU} / \mathrm{mL})$ and anti-thyroglobulin antibody was positive. The endoscopy of upper gastrointestinal tract showed Grade I esophageal varices and the biopsy was taken from the second part of duodenum to exclude celiac disease.

Dr. Dey: Histopathology of duodenal tissue showed marked villous atrophy with crypt hyperplasia. There was moderate infiltration of lymphocytes within epithelial lining (>30 IEL/100 enterocytes). The lamina propria revealed marked infiltration of chronic inflammatory cells including plasma cells (Figure 1B). These features go in favor of celiac disease (Marsh score 3b).

\section{Dr. Benzamin's Diagnosis}

Chronic liver disease with portal hypertension with coagulopathy due to autoimmune hepatitis with grade III esophageal varices with autoimmune thyroiditis with celiac disease.

The treatment was prednisolone (tablet, $2 \mathrm{mg} / \mathrm{kg} /$ day), propranolol (tablet, $1 \mathrm{mg} / \mathrm{kg} /$ day), thyroxine (tablet, $2 \mathrm{mg} / \mathrm{kg}$ ), ursodeoxycholic acid (tablet, 20 $\mathrm{mg} / \mathrm{kg}$ ) and azathioprine (tablet, $2 \mathrm{mg} / \mathrm{kg} /$ day)

Table II

\section{Proposed criteria for the diagnosis of autoimmune hepatitis}

\begin{tabular}{|lrr|}
\hline Variable & Cut-off & Points \\
\hline Anti-nuclear antibody & $\geq 1: 20$ & 1 \\
and/or anti-smooth muscle antibody & $\geq 1: 80$ & 2 \\
Anti-liver kidney microsomal antibody-1 & $\geq 1: 20$ & 1 \\
& $\geq 1: 80$ & 2 \\
Anti-liver cytosol type-1 & + & 2 \\
Anti-soluble liver antigen & + & 2 \\
Peripheral antinuclear neutrophil anti- & + & 1 \\
body & mal & 1 \\
IgG & >upper limit of nor- & 1 \\
& mormal & 2 \\
& Compatible with & 1 \\
Liver histology & autoimmune hepatitis & \\
& Typical of autoim- & 2 \\
& mune hepatitis & \\
Absence of viral hepatitis (A, B,C, E, Ep- & Yes & 2 \\
stein-Barr virus), non-alcoholic steatohep- & & \\
atitis, Wilson's disease, and drug exposure & & 1 \\
Presence of extrahepatic autoimmunity & & 1 \\
Family history of autoimmune disease & Normal & 2 \\
Cholangiography & -2 \\
& Abnormal & \\
Score 7: probable autoimmune hepatitis; Score 8: definite autoimmune hepatitis9,34 & \\
\hline
\end{tabular}

was given 2 weeks after starting prednisolone along with gluten free diet.

\section{Discussion}

Dr. Md. Rukunuzzaman (Professor): Autoimmune hepatitis is one of the prototypes of autoimmune liver disease. It was first described in 1950.15-17 In autoimmune hepatitis, progressive immune mediated inflammatory tissue damage occurs due to loss of self-tolerance.18 Autoimmune hepatitis can occur at any age group, the peak incidence occurs at the ages of 16 to 30 years.10-13, 20 Females are affected more than males, ratio of 3.6:1.13 In Scandinavia, prevalence is 1 to 2 cases/100,000 populations/year with a point prevalence of 11 to 17 cases/year. $\underline{11,19}$ Canada has an annual incidence of pediatric autoimmune hepatitis of 0.23 case/100,000 children.20 In Bangladesh, Benzamin et al. (2018) found about $8 \%$ of children with chronic liver disease with hepatomegaly with/without splenomegaly are due to autoimmune hepatitis. $\underline{21}$

On the basis of autoantibody, autoimmune hepatitis has 2 subtypes: type 1 and 2. Type 1 autoimmune hepatitis presents at puberty and accounts for two third of cases. Type 1 autoimmune hepatitis is positive for antinuclear antibody and/or anti smooth muscle antibody. Type 2 autoimmune hepatitis usually occurs in younger age and during infancy. Type 2 autoimmune hepatitis is positive for anti-liver kidney microsomal and/or anti-liver cytosol 1 antibody. $\underline{22,23}$

Autoimmune hepatitis has variable clinical presentation from asymptomatic raised alanine transaminase or features of acute hepatitis to chronic liver disease. Acute presentation with malaise, nausea, anorexia, vomiting, joint pain, abdominal pain, followed by jaundice, dark urine, pale stool (40-50\%). Children also present as chronic liver disease or with complications of cirrhosis and portal hypertension. About $10 \%$ of chronic patients have no previous history of liver disease and jaundice. Non-specific symptoms of progressive fatigue, relapsing jaundice, amenorrhea, headache, anorexia, joint pain, abdominal pain, diarrhea, weight loss may be associated. Some patients present as fulminant hepatic failure.20, 24-29 Autoimmune hepatitis should be suspected when all causes of acute and chronic hepatitis are excluded. 9

Diagnosis of autoimmune hepatitis is made by combination of clinical, biochemical, immunological and histological features and exclusion of other liver diseases like Wilson's disease, viral hepatitis, nonalcoholic steatohepatitis and drug induced liver disease. Liver biopsy is required to confirm the diagnosis, to evaluate the severity of liver disease and to see treatment response. $., 13,14$ 
Presence of auto antibody is the key of diagnosis. In autoimmune hepatitis, IgG level is raised, auto antibody like antinuclear antibody, anti-smooth muscle antibody, anti-liver kidney microsomal antibody, anti-liver cytosol antibody, antimitochondrial antibody may be positive. $., 22,23$ Other antibodies that are less commonly tested: antisoluble liver antigen (anti-SLA), antiperinuclear neutrophil cytoplasm antibody (pANCA). Anti-SLA is specific for autoimmune hepatitis and positive predictor of worse outcome. $.30-32$

Dr. Dey: Histological features of autoimmune hepatitis ranges from typical findings to uncommon morphological findings. Typical morphological changes include- periportal plasma cell rich inflammation, Interface hepatitis/piecemeal necrosis (portal inflammatory cells eroding through the limiting plate between the portal tract and liver parenchyma), emperipolesis (engulfment of lymphocytes by hepatocytes), hepatocyte rosette formation, variable fibrosis (about 10\% of autoimmune hepatitis does not show any fibrosis at initial presentation), lobular necro-inflammatory activity (shows by portal and periportal inflammation). $\underline{33}$ 0ther uncommon morphological changes include-perivascular necrosis, intrahepatic cholestasis, syncytial multinucleated giant cells, mild bile duct injury (present up to $24 \%$ of classical autoimmune hepatitis). Perivascular necrosis present in up to $17 \%$ of autoimmune hepatitis with or without typical portal and periportal changes; usually associated with more severe disease activity and lower histological stage. Autoimmune hepatitis is the most common cause $(30 \%)$ of postinfantile giant cell hepatitis. Overlap syndrome or chronic biliary disease only need to be considered in the presence of more extensive bile duct injury, ductular reaction, florid duct lesion, ductopenia, chronic cholate stasis, portal granulomas or periductal fibrosis. $\underline{33}$

Dr. Rukunuzzaman: Recently, a scoring system for the diagnosis of autoimmune liver disease in pediatric age is proposed by ESPGHAN.

Dr. Khan Lamia Nahid (Assistant Professor): There is association of autoimmune diseases at disease presentation or eventually develop during followup. The diseases include thyroiditis, hemolytic disease, inflammatory bowel disease, vitiligo, insulin dependent diabetes mellitus, coeliac disease, behcet syndrome, Sjogren syndrome, idiopathic thrombocytopenia, hypoparathyroidism, glomerulonephritis, urticarial pigmentosa, Addison disease which is mainly present in autoimmune hepatitis 2. This should be addressed properly in course of the treatment. Association of hypothyroidism is present up to $23 \%$ patients, Coeliac disease is associated with autoimmune hepatitis up to $10 \%$ cases. IBD is reported in $18 \%$ of patients. $\underline{9,24,26,35}$
Dr. Mohammad Ahmadur Rahman: After establishing the diagnosis of autoimmune hepatitis, treatment should be started promptly to avoid progression of disease. Autoimmune hepatitis is responsive to immunosuppressive drug. Treatment consists of two parts- induction of remission and maintenance phase. The conventional treatment includes prednisolone tablet $2 \mathrm{mg} / \mathrm{kg} /$ day (maximum 60 $\mathrm{mg} /$ day) and azathioprine. Prednisolone decreases in parallel to decline of serum alanine aminotransferase over a period of 4 to 8 weeks, maintenance dose of prednisolone will be 2.5 to $5 \mathrm{~g} /$ day. For adjustment of prednisolone dose, liver function tests should be done frequently, preferably weekly. Azathioprine tablet is added 0.5 to $2 \mathrm{mg} / \mathrm{kg} /$ day, 2 weeks after starting prednisolone. $.9,13,14,36,37$

Dr. Ayesha Siddiqua (Resident): Why azathioprine not started along with prednisolone??

Dr. Nahid: In the beginning, azathioprine can't be started as it has hepatotoxic effect particularly in cirrhotic and severely icteric patient. $1 \underline{14}$

Dr. Nyema Rahman (Resident): Is there any other protocol for treatment?

Dr. Dipanwita Saha (Resident): Other protocols include a) prednisolone plus azathioprine from starting or b) budesonide plus azathioprine from starting or c) cyclosporine A for 6 months followed by addition of prednisolone plus azathioprine. $\underline{9,38-40}$

Dr. Rafia Rashid (Resident): What is the treatment option if medical therapy fails?

Dr. Nahid-E-Subha (Resident): Liver transplantation is needed when medical treatment fails, also in acute liver failure. 9

Dr. Nazmul Hossain (Resident): On which protocol, remission is more achieved with less side effects?

Dr. Ruhina Tasmeen (Research Assistant): After being treated with prednisolone for 6 to 9 months, 75 to $90 \%$ of patients are able to achieve normal liver function. Treatment with azathioprine and prednisolone from diagnosis, has more side effects $(93 \%)$ and a higher relapse rate $(67 \%)$ than autoimmune hepatitis children treated with steroid induction followed by azathioprine addition (relapse rate $33-36 \%$; side effects $18-38 \%$ )..24, 26

Dr. Raihanur Rahman (Resident): How remission and relapse is defined?

Dr. Nahid-E-Subha: Complete remission is defined as clinical recovery, normal serum alanine aminotransferase, IgG level, negative or very low titer of autoantibodies, histologically resolution of inflammation. Relapse is defined as an increase in serum alanine aminotransferase after remission, it occurs in $40 \%$ patients. $., 27,41$

Dr. Archana Shrestha Yadav (Resident): Why did you 
do duodenal biopsy?

Dr. Hazera Akther (Resident): About 5-10\% of autoimmune hepatitis is associated with celiac disease. In our patient, although tissue Transglutaminase- IgA was negative, partial IgA deficiency may be present in $40 \%$ cases of type 1 autoimmune hepatitis. So, to diagnose association of celiac disease we did duodenal biopsy..$\underline{26}$

Dr. Naznin Akhter (Resident): What others finding may be found on duodenal biopsy regarding celiac disease?

Dr. Dey: Histological diagnostic points are increased intraepithelial $\mathrm{T}$ lymphocytes, crypt hyperplasia (increased number of the regenerative epithelial crypts present with changes and usually shows more than 1 mitosis per crypt), villous atrophy (reduced in villous height, alteration of normal crypt/villous ratio-3:1). Intraepithelial $\mathrm{T}$ lymphocytes 25 to 29 IEL/100 enterocytes is considered, borderline; >30 IEL/100 enterocytes considered as a pathological "lymphocytosis". Decreased enterocyte height, flattening of enterocytes, intracytoplasmic vacuoles and reduction or absence of brush border are suggestive of celiac disease but not specific. Based on these elementary lesions, Modified Marsh-Oberhuber classification of histologic findings in celiac disease: a) Grade A/type 1: increased intraepithelial lymphocytes but no villous atrophy. b) Grade B1/ type 2: villi still present but shortened. c) Grade B2/ type 3: complete villous atrophy. $\underline{42}$

Dr. Subarna Rani Das (Resident): What is the relation of celiac disease with treatment outcome of autoimmune hepatitis?

Dr. Kaniz Fathema (Resident): Gluten-free diets may have a possible long-term adjuvant effect on autoimmune hepatitis treatment outcome. Patients with autoimmune hepatitis and celiac disease have been reported to achieve treatment-free sustained remission more than patients with autoimmune hepatitis without celiac disease. $\underline{43}$

Dr. Akhter: How you will monitor?

Dr. Md. Saidul Islam (Resident): After successful withdrawal of therapy, continue monitoring with serum transaminase level, IgG, autoantibodies 3 monthly for at least 5 years. 9

Dr. Urmi Roy (Resident): What is the prognosis?

Dr. Parisa Marjan (Resident): The prognosis of autoimmune hepatitis is generally good. Most of the patients survive excellent quality of life with treatment. About 8 to $16 \%$ of children complain to immunosuppressive therapy and without any evidence, biochemical relapse may develop Endstage liver disease (cirrhosis). In our patient, she developed ascites and portal hypertension along with other immune mediated disease, so prognosis is guarded. $.6,44$

\section{Follow-up}

Patient was improved clinically and biochemically after 3 months of treatment and then further treatment continues accordingly.

\section{Final Diagnosis}

Chronic liver disease with portal hypertension with coagulopathy due to autoimmune hepatitis with grade III esophageal varices with autoimmune thyroiditis with celiac disease.

\section{Conflict of Interest}

The authors declare no conflict of interest.

\section{Acknowledgement}

We are grateful to Prof. Mohammed Kamal, Department of Pathology, Bangabandhu Sheikh Mujib Medical University, Dhaka, Bangladesh for histopathological examination.

\section{References}

1. Tao TY, Gitlin JD. Hepatic copper metabolism: Insights from genetic disease. Hepatology 2003; 37: 1241-47.

2. Wilson DC, Phillips MJ, Cox DW, Roberts EA. Severe hepatic Wilson's disease in preschool-aged children. J Pediatr 2000; 137: 719-22.

3. Ala A, Walker AP, Ashkan K, Dooley JS, Schilsky ML. Wilson's disease. Lancet 2007; 369: 397-408.

4. Kathawala M, Hirschfield GM. Insights into the management of Wilson's disease. Therap Adv Gastroenterol. 2017; 10: 889-905.

5. Rukunuzzaman M. Wilson's disease in Bangladeshi children: Analysis of 100 cases. Pediatr Gastroenterol Hepatol Nutr. 2015; 18: 121-27.

6. Bayes F, Karim ASMB, Helaly L, Bayes F, Rukunuzzaman M, Ahmed S, Alam ST. Spectrum of hepatic presentation of Wilson's disease in children attending a tertiary care centre of Dhaka City. Bangladesh J Child Health. 2014; 38: 86-93.

7. Marjan $\mathrm{P}$, Rukunuzzaman M, Karim ASMB, Mondal M, Akter H. A 9-year-old girl presented with jaundice, abdominal distension, hematemesis, melena and pleural effusion. Bangabandhu Sheikh Mujib Med Univ J. 2018; 11: 300-03.

8. European association for study of liver. Clinical practice guideline: Wilson's disease. J Hepatol. 
2012; 56: 671-85.

9. Mieli-Vergani G, Vergani D, Baumann U, Czubkowski P, Debray D, Dezsofi A, Fischler B, Gupte G, Hierro L, Indolfi G, Jahnel J, Smets F, Verkade HJ, Hadžić N. Diagnosis and management of pediatric autoimmune liver disease: ESPGHAN hepatology committee position statement. J Pediatr Gastroenterol Nutr. 2018; 66: 345-60.

10. Boberg KM, Aadland E, Jahnsen J, Raknerud $\mathrm{N}$, Stiris $\mathrm{M}$, Bell $\mathrm{H}$. Incidence and prevalence of primary biliary cirrhosis, primary sclerosing cholangitis, and autoimmune hepatitis in a Norwegian population. Scand J Gastroenterol. 1998; 33: 99-103.

11. Werner M, Prytz H, Ohlsson B, Almer S, Björnsson E, Bergquist A, Wallerstedt S, SandbergGertzén H, Hultcrantz R, Sangfelt P, Weiland $\mathrm{O}$, Danielsson A. Epidemiology and the initial presentation of autoimmune hepatitis in Sweden: A nationwide study. Scand J Gastroenterol. 2008; 43: 1232-40.

12. Al-Chalabi T1, Boccato $S$, Portmann BC, McFarlane IG, Heneghan MA. Autoimmune hepatitis $(\mathrm{AIH})$ in the elderly: A systematic retrospective analysis of a large group of consecutive patients with definite $\mathrm{AIH}$ followed at a tertiary referral centre. J Hepatol. 2006; 45: 575-83.

13. Manns MP, Czaja AJ, Gorham JD, Krawitt EL, Mieli -Vergani G, Vergani D, Vierling JM. Diagnosis and management of autoimmune hepatitis. Hepatology 2010; 51: 2193-213.

14. European association for the study of the liver. EASL clinical practice guidelines: Autoimmune hepatitis. J Hepatol 2015; 63: 971-1004.

15. Mackay IR, Taft LI, Cowling DC. Lupoid hepatitis. Lancet 1956; ii: 1323-26.

16. Joske RA, King WE. The L.E.-cell phenomenon in active chronic viral hepatitis. Lancet 1955; 269: 47780

17. Mackay IR. Chronic active hepatitides. Front Gastrointest Res. 1975; 1: 142-87.

18. Fernández MIC, Hernández DR, Eugenio DEC, Palanca W, Guridi ZD, Fabián LG. Diagnosis and treatment of autoimmune liver diseases in a tertiary referral center in Cuba. Curr Therap Res. 2017; 85: 8 -14 .

19. Miele-Vergani G, Vergani D. Autoimmune hepatitis in childhood. Clin Liver Dis. 2014; 3: 6-8.

20. Jiménez-Rivera C, Ling SC, Ahmed N, Yap J, Aglipay M, Barrowman N, Graitson S, Critch J, Rashid M, Ng VL, Roberts EA, Brill H, Dowhaniuk JK, Bruce G, Bax K, Deneau M, Guttman OR, Schreiber RA, Martin S, Alvarez F. Incidence and characteristics of autoimmune hepatitis. Pediatrics 2015; 136: e1237-48.

21. Benzamin M, Sayeed M, Islam MS, Alam R, Rukunuzzaman M, Mazumder MW, Karim ASMB. Study of etiological profile of children presented with hepatomegaly and/or splenomegaly: An experience from Pediatric Gastroenterology Department, Bangabandhu Sheikh Mujib Medical University. Paediatr Nephrol J Bangladesh. 2018: 3: 9-17.

22. Vergani D, Alvarez F, Bianchi FB, Cançado EL, Mackay IR, Manns MP, et al. Liver autoimmune serology: A consensus statement from the committee for autoimmune serology of the International Autoimmune Hepatitis Group. J Hepatol. 2004; 41: 677-83.

23. Villalta D, Girolami E, Alessio MG, Sorrentino MC, Tampoia M, Brusca I, Daves M, Porcelli B, Barberio G, Conte M, Pantarotto L, Bizzaro N. Autoantibody profiling in a cohort of pediatric and adult patients with autoimmune hepatitis. J Clin Lab Anal. 2016; 30: 41-46.

24. Gregorio GV, Portmann B, Karani J, Harrison P, Donaldson PT, Vergani D, Mieli-Vergani G. Autoimmune hepatitis/sclerosing cholangitis overlap syndrome in childhood: A 16-year prospective study. Hepatology 2001; 33: 544-53.

25. Di Giorgio A, Bravi M, Bonanomi E, Alessio G, Sonzogni A, Zen Y, Colledan M, D'Antiga L. Fulminant hepatic failure of autoimmune aetiology in children. J Pediatr Gastroenterol Nutr. 2015; 60: 159 -64 .

26. Gregorio GV, Portmann B, Reid F, Donaldson PT, Doherty DG, McCartney M, Mowat AP, Vergani D, Mieli-Vergani G. Autoimmune hepatitis in childhood: A 20-year experience. Hepatology 1997; 25: 541-47.

27. Mieli-Vergani G, Heller S, Jara P, Vergani D, Chang $\mathrm{MH}$, Fujisawa T, González-Peralta RP, Kelly D, Mohan N, Shah U, Murray KF. Auto-immune hepatitis. J Pediatr Gastroenterol Nutr. 2009; 49: 158 -64 .

28. Ramachandran J, Sajith KG, Pal S, Rasak JV, Prakash JA, Ramakrishna B. Clinicopathological profile and management of severe autoimmune hepatitis. Trop Gastroenterol. 2014; 35: 25-31.

29. Brissos J, Carrusca C, Correia M, Cabral J. Autoimmune hepatitis: Trust in transaminases. BMJ Case Rep. 2014; 2014.

30. Bogdanos DP, Mieli-Vergani G, Vergani D. Autoantibodies and their antigens in autoimmune hepatitis. Semin Liver Dis. 2009; 29: 241-53.

31. Liberal R, Mieli-Vergani G, Vergani D. Clinical significance of autoantibodies in autoimmune hepatitis. J Autoimmun. 2013; 46: 17-24.

32. Ma Y, Okamoto $M$, Thomas MG, Bogdanos DP, Lopes AR, Portmann B, Underhill J, Dürr R, MieliVergani G, Vergani D. Antibodies to conformational epitopes of soluble liver antigen define a severe form of autoimmune liver disease. Hepatology 2002; 35: 658-64.

33. Theise ND. Liver and gall bladder: Autoimmune hepatitis. In: Robins and Cortan Pathologic basis of disease. Kumer V, Abbas AK, Aster JC (eds). 9th ed. 
Philadelphia, Elsevier Inc, 2015, pp 839-41.

34. Radhakrishnan KR, Alkhouri N, Worley S, Arrigain S, Hupertz V, Kay M, Yerian L, Wyllie R, Feldstein AE. Autoimmune hepatitis in children-impact of cirrhosis at presentation on natural history and long -term outcome. Dig Liver Dis. 2010; 42: 724-28.

35. Wong GW, Heneghan MA. Association of extrahepatic manifestations with autoimmune hepatitis. Dig Dis. 2015; 33: 25-35.

36. Mieli-Vergani G, Vergani D. Paediatric autoimmune liver disease. Arch Dis Child. 2013; 98: 1012-17.

37. Czaja AJ, Bianchi FB, Carpenter HA, Krawitt EL, Lohse AW, Manns MP, McFarlane IG, MieliVergani G, Toda G, Vergani D, Vierling J, Zeniya M. Treatment challenges and investigational opportunities in autoimmune hepatitis. Hepatology 2005 41: 207-15.

38. Woynarowski M, Nemeth A, Baruch Y, Koletzko S, Melter M, Rodeck B, Strassburg CP, Pröls M, Woźniak M, Manns MP. Budesonide versus prednisone with azathioprine for the treatment of autoimmune hepatitis in children and adolescents. J Pediatr. 2013; 163: 1347-53.

39. Alvarez F, Ciocca M, Cañero-Velasco C, Ramonet M, de Davila MT, Cuarterolo M, Gonzalez T, Jara-
Vega P, Camarena C, Brochu P, Drut R, Alvarez E. Short-term cyclosporine induces a remission of autoimmune hepatitis in children. J Hepatol. 1999; 30: 222-27.

40. Cuarterolo M, Ciocca M, Velasco CC, Ramonet M, González T, López S, Garsd A, Alvarez F. Follow-up of children with autoimmune hepatitis treated with cyclosporine. J Pediatr Gastroenterol Nutr. 2006; 43: 635-639.

41. Lee WS, Lum SH, Lim CB, Chong SY, Khoh KM, Ng RT, Teo KM, Boey CCM, Pailoor J. Characteristics and outcome of autoimmune liver disease in Asian children. Hepatol Int. 2015; 9: 292-302.

42. Turner JR. The gastrointestinal tract: Celiac Disease. In: Robins and Cortan Pathologic basis of disease. Kumer V, Abbas AK, Aster JC (eds). 9th ed. Philadelphia, Elsevier Inc, 2015, pp 782-85.

43. Nastasio S, Sciveres M, Riva S, Filippeschi IP, Vajro P, Maggiore G. Celiac disease-associated autoimmune hepatitis in childhood: Long-term response to treatment. J Pediatr Gastroenterol Nutr. 2013; 56: 671-74.

44. Saadah OI, Smith AL, Hardikar W. Long-term outcome of autoimmune hepatitis in children. J Gastroenterol Hepatol. 2001; 16: 1297-302. 